\title{
Non-hematological Adverse Events of I matinib in Patients with Chronic Myeloid Leukemia in Chronic Phase (CML-CP)
}

\author{
Mehrdad Payandeh $^{1}$, Edris Sadeghi ${ }^{2 *}$, Masoud Sadeghi ${ }^{2}$ \\ ${ }^{1}$ Department of Hematology-Oncology, Kermanshah University of Medical Sciences, Kermanshah, Iran. \\ ${ }^{2}$ Students Research Committee, Kermanshah University of Medical Sciences, Kermanshah, Iran.
}

\section{ARTICLE INFO \\ Article history: \\ Received on: 06/11/2014 \\ Revised on: 24/12/2014 \\ Accepted on: 17/01/2015 \\ Available online: 27/02/2015}

Key words:

Chronic myeloid leukemia,

Fatigue, Imatinib, Myalgia

\begin{abstract}
The aim of this study is survey of effects of Imatinib with dose $400 \mathrm{mg}$ per day after 6 months in the patients with CML chronic phase. Between of 2010 - 2014, fifty four patients with high risk CML referred to Taleghani hospital in Kermanshah, Iran. We used the questionnaire about adverse events (AEs) of Imatinib capsule (Cipla manufacture, India) in these patients. For grading AEs, We used Common Terminology Criteria for AEs (CTCAE) manuscript (low AE equals grade 1, 2: high AE equals 3, 4 and grade 5 is optional) that diagram related to them was plotted with Excel 2007 software. 54 patients that referred to hospital, 27 patients were female and 27 patients were male. Mean of age for the patients was $45.7 \pm 13.8$ years (range, 23 to 78 years). Fatigue, $(66.7 \%)$, myalgia $(61.6 \%)$, joint pain $(61.6 \%)$ and cramp $(57.4 \%)$ are the most AEs in the patients after treatment of Imatinib. In the future studies we should evaluate non-hematological AEs for Imatinib in a lot of CML patients and apply to CTCAE manuscript exactly.
\end{abstract}

\section{INTRODUCTION}

Chronic myeloid leukemia (CML) is a chronic disease that about $50 \%$ of patients are more than 60 years old, and about $50 \%$ of patients are asymptomatic (Baccarani et al., 2013). In the patients with CML, the introduction of targeted therapy using tyrosine kinase inhibitors (TKI), the majority of patients remain in long-term complete remission. However, the discontinuation of the therapy usually leads to disease relapse which indicates that the residual disease remains to be a major issue in CML management (Mauro, 2013) The first approved TKI was Imatinib Mesylate (Glivec or Gleevec), that is still the CML standard treatment for many-patients and the structure of Imatinib has been shown in Fig. 1 (Baccarani et al., 2013). Imatinib, a tyrosine kinase inhibitor, was called as "magical bullet," when it revolutionized the treatment of chronic myeloid leukemia (CML)

\footnotetext{
* Corresponding Author

Corresponding author: Edris Sadeghi, Researcher in Medical Sciences Medical Biology Research Center, Kermanshah University Medical Sciences, Kermanshah, Iran.E-Mail: sadeghi_mkn@yahoo.com
}

in 2001, and it was invented in the late 1990s by biochemist Nicholas Lyndon and its use to treat CML was driven by Brian Druker. Encouraged by the success of Imatinib in treating CML patients, scientists explored its effect in other cancers and it was found to produce a similar miracle effect in other cancers where tyrosine kinases were over expressed. (Iqbal and Iqbal, 2014) In other hand, Imatinib was one of the first cancer therapies to show the potential for such targeted action, and is often cited as a paradigm for research in cancer therapeutics (Stegmeier et al., 2010). Imatinib(Indian generic) was started at a dose of $400 \mathrm{mg}$ in our patients with CML chronic phase. The most commonly observed non-hematologic AEs include nausea, vomiting, diarrhea, muscle cramps, fluid retention, skin rash, and fatigue other less common AEs, such as liver and kidney toxicity, have also been reported in the literature (Foringer et al., 2005). The side effects of TKIs are reported as 'tolerable' and 'manageable', but when the AEs, even minimal, even mild, are chronic, the quality of life and the compliance to treatment will be affected (Talpaz et al., 2013). To optimize Imatinib treatment and the understanding of CML, the European treatment and outcome study for CML 
(EUTOS) was launched as a scientific collaboration between the Euro-pean LeukemiaNet (ELN) and the manufacturer of the drug. (Anonyms, 2008) In this study, we reported non-hematologic AEs (AEs) of Imatinib in CML chronic phase patients in Kermanshah province, Iran.

\section{Patients and Methods}

The study was conducted from 2010 to 2014; during this period, fifty four patients with high risk CML referred to Taleghani hospital in Kermanshah, Iran. We gathered data with using the questionnaire about AEs of Imatinib capsule (Cipla manufacture, India) that medical oncologist prescribed to them for a period of time sex months with dose $400 \mathrm{mg}$ per day as first line therapy. Non-hematologic AE of Imatinib includes: fatigue(most), weakness and lethargy, myalgia, joint pain(knee-ankle-elbow), cramp, bone pain, swelling of face, insomnia, depression, abdomen pain, nausea, swollen hands and feet, constipation, weight loss, vomiting, cough, weight gain, fever, rash and hives, weld, throat infection, diarrhea, sinusitis, blood in the stoolvomiting blood and urinary retention(lowest). Grade refers to the severity of the AE: asymptomatic or mild symptoms; clinical or diagnostic observations only; intervention not indicated (Grade 1 or Mild). Minimal, local or noninvasive intervention indicated; limiting age-appropriate instrumental Activities of Daily Living (ADL)(Grade 2 or Mild). medically significant but not immediately life-threatening; hospitalization or prolongation of hospitalization indicated; disabling; limiting self care ADL(Grade 3 or severe). Life-threatening consequences; urgent intervention indicated (Grade 4). We regardless grade 5 based on CTCAE. In our study, the patients with low AE are located in grade 1 or 2 and the patients with high AE are located in grade 3 or 4 . We used Excel 2007 software for drawing of diagram.

\section{RESULTS}

In this study, 54 patients with CML in the chronic phase were included; 27 patients were female and 27 patients were male. Mean of age for the patients was $45.7 \pm 13.8$ years (range, 23 to 78 years) (Table 1). The Table 2 shows different AEs of Imatinaib capsule that and also Fig. 2 shows grading of AEs that we separate them two level, low AE and high AE.

The Table 2 shows that fatigue, weakness and lethargy, myalgia, joint pain (knee-ankle-elbow) and cramp observe in more of $50 \%$ of patients.

\section{DISCUSSION}

Imatinib produces a high effect in the course of CML (Baccarani et al., 2014). It is a very powerful medication, so AEs can be expected to occur (Valizadeh, 2011). A study (Mozaheb, 2014) in Iran showed that fluid retention (64\%), fatigue (43\%), musculoskeletal pain $(41 \%)$, skin rush $(35 \%)$, nausea $(21 \%)$ were the most common non-hematologic side effects for
Imatinib in the CML patients but in our study were fatigue, weakness and lethargy $(66.7 \%)$, myalgia $(61.6 \%)$, joint pain(kneeankle-elbow)(61.6\%) and cramp (57.4\%). A study in India (Gupta and Prasad, 2007) reported edema and arthralgia as their predominant adverse effects (Moshfeghi et al., 2013). reported that the most prevalent adverse effects of Imatinib in previous studies were edema, nausea, cramp, rash, and diarrhea, which occurred in $29-60 \%$ of the patients with CML, and other study in Iran reported frequency of common adverse effects observed for the Indian and Iranian kinds of the drug in the study were as follows: edema (facial edema was more prevalent) (62.7 vs. 63.7\%), GI symptoms (41.9 vs. $39.1 \%$ ), fatigue and headache (40.6 vs. $43.2 \%$ ), mood symptoms (11.6 vs. 15.6\%), and hematological complications (9.3\% in both kinds) (Moshfeghi et al., 2013; Hattab, 2013). Is reported skin rush was $19.9 \%$. In the IRIS (international randomized study of interferon) study, $30 \%$ of the patients had grades 3/4 AEs that included fatigue, depression, myalgia, arthralgia,( O'Brien et al ., 2003) whereas in our study $24 \%, 5.5 \%$, $13 \%$ and $11 \%$ of the patients had those signs in high AEs, respectively. Also in low AEs we observed them with more density, $42.5 \%, 24 \%, 48 \%, 50 \%$, respectively and other study reported just fatigue (43\%) (Talpaz et al., 2013). There were no reports of nausea, muscle cramps, joint pain, and skin hypo pigmentation (Jalaeikhoo et al., 2011) whereas in our study was reported nausea $(25.9 \%)$, cramp $(57.4 \%)$, joint pain $(61.6 \%)$ and skin hypo pigmentation(31.5\%) that it is apposite of report of Jalaeikhoo et al. (Jalaeikhoo et al., 2011). but approximately was similar to report of O'Brien SG et al.[ O'Brien et al., 2003] In a Iranian study which were used generic Imatinib, like our study, AEs were: edema (63\%), GI symptoms (40\%), fatigue and headache (40\%) and mood symptoms (13\%)( Moshfeghi et al., 2013). Elderly female patients had higher Imatinib concentrations and more AEs (Gotta et al., 2014). There is reduction in the risk of non-hematological AEs with early treatment, including weight gain $(11 \%)$, periorbital edema $(12 \%)$, rash $(9 \%)$, diarrhea $(11 \%)$, and bone pain $(8 \%)$ (Breccia et al, 2008). Common AEs of Imatinib were relatively similar and comparable to others. All these differences may be due to the effect of biological, environmental, or socioeconomic factors, and/or the Imatinib which was used. we showed a higher efficacy and safety of Imatinib therapy among Iranian patients with CML (Jalaeikhoo et al., 2011). In Table 2, we observed 24 AEs related to Imatinib capsule that some of them is observed in CML chronic phase patients rarely like Sinusitis(5.6\%), blood in the stool-vomiting blood(3.7\%), urinary retention(1.9\%). We saw constipation in 12 patients from all patients were under our study so based on our knowledge, it is a new AE for Imatinib. As we can see in Table 1 the mean age of our patients (Kermanshah, Iran) was 45.7 (range 23- 78) years at diagnosis but is more than some reports from eastern. In a study, age at diagnosis differed within Asia, in western Asia 44.4 years, southeastern Asia 39.5, eastern Asia 38.4, south-central Asia 37.8 were reported (Mendizabal et al., 2013). 


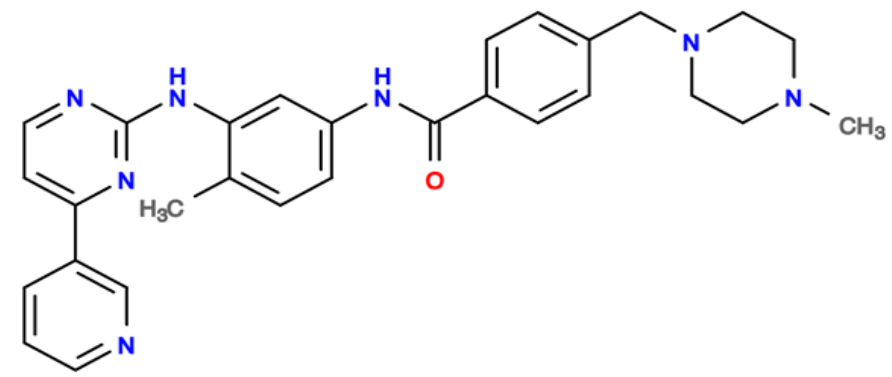

Fig. 1: Chemical structure of Imatinib.

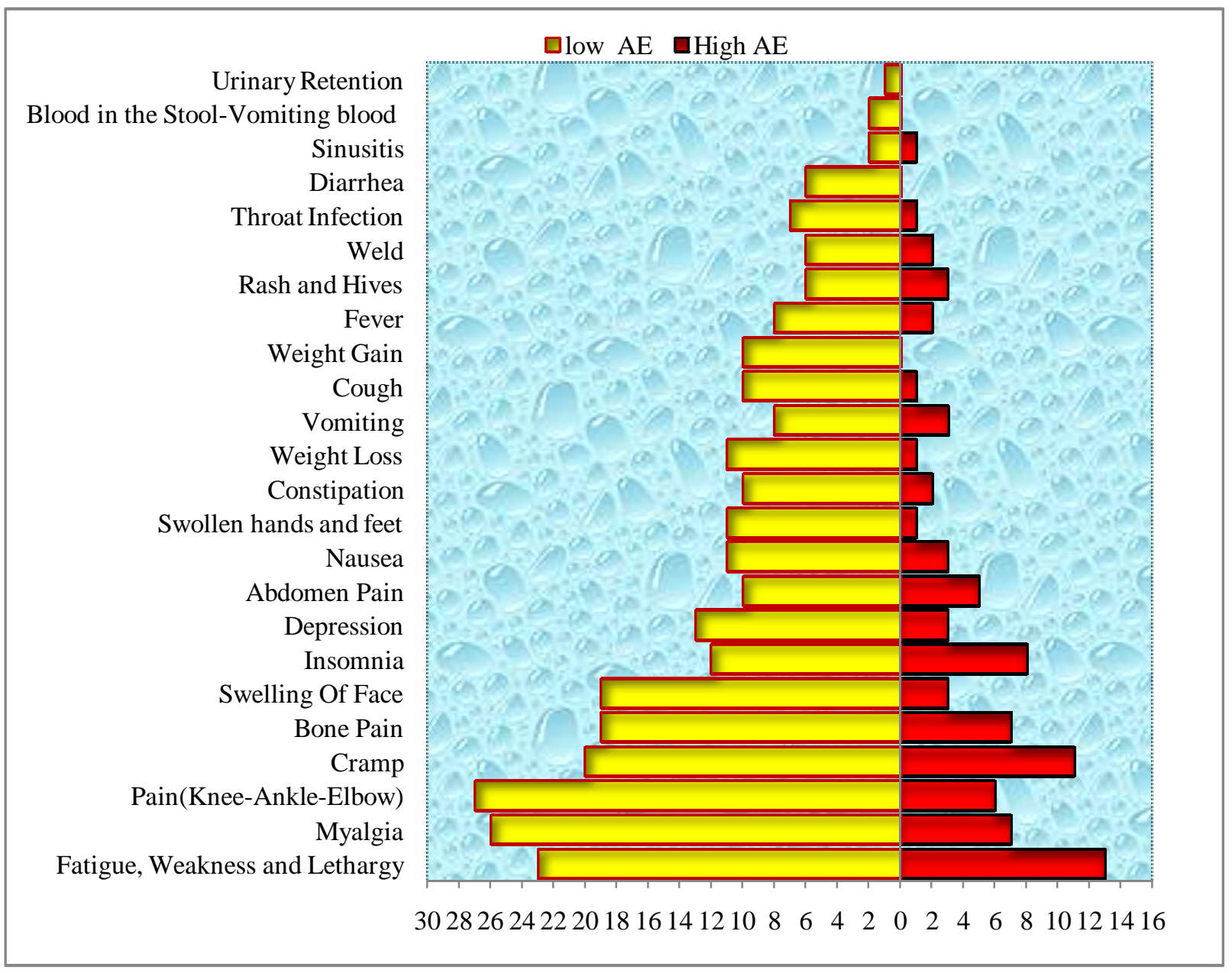

Fig. 2: Tow grading for AEs of Imatinib in CML chronic phase patients.

Table 1: Characteristic of the 54 patients with CML

\begin{tabular}{|c|c|}
\hline Characteristic & $\mathrm{n}(\%)$ \\
\hline \multicolumn{2}{|c|}{ Sex } \\
\hline Male & 27 \\
\hline Female & 27 \\
\hline \multicolumn{2}{|c|}{ Age(year) } \\
\hline Min & 23 \\
\hline Max & 78 \\
\hline Mean & $45.7 \pm 13.8$ \\
\hline
\end{tabular}


Table 2: Common non-hematologic side effects of Imatinib $(\mathrm{n}=54)$.

\begin{tabular}{|c|c|c|c|}
\hline Non-hematologic $A E$ & $n(\%)$ & Non-hematologic $A E$ & $n(\%)$ \\
\hline Fatigue, Weakness and Lethargy & $36(66.7)$ & Weight Loss & $12(22.2)$ \\
\hline Myalgia & $33(61.6)$ & Vomiting & $11(20.4)$ \\
\hline Joint Pain (Knee-Ankle-Elbow) & $33(61.6)$ & Cough & $11(20.4)$ \\
\hline Cramp & $31(57.4)$ & Weight Gain & $10(18.5)$ \\
\hline Bone Pain & $26(48.1)$ & Fever & $10(18.5)$ \\
\hline Swelling Of Face & $22(40.7)$ & Rash and Hives & $9(16.7)$ \\
\hline Insomnia & $20(37.0)$ & Weld & $8(14.8)$ \\
\hline Depression & $16(29.6)$ & Throat Infection & $8(14.8)$ \\
\hline Abdomen Pain & $15(27.8)$ & Diarrhea & $6(11.1)$ \\
\hline Nausea & $14(25.9)$ & Sinusitis & $3(5.6)$ \\
\hline Swollen hands and feet & $12(22.2)$ & Blood in the Stool-Vomiting Blood & $2(3.7)$ \\
\hline Constipation & $12(22.2)$ & Urinary Retention & 1(1.9) \\
\hline
\end{tabular}

\section{CONCLUSIONS}

Fatigue and Myalgia are the most AEs for Imatinib in the patients of CML. Therefore, in the future studies we should evaluate AEs for Imatinib in a lot of CML patients and express grading more accurate.

\section{ACKNOWLEDGMENT}

There is no acknowledgment.

\section{REFERENCES}

Anonyms. EUTOS for chronic myeloid leukemia shows improved management and dose optimization is required. Future Oncol, 2008 Dec;4(6):758.

Baccarani M, Castagnetti F, Gugliotta G, Palandri F \& Rosti G. Treatment recommendations for chronic myeloid leukemia. Mediterr J Hematol Infect Dis, 2014 Jan 2;6(1):e2014005.

Baccarani M, Deininger MW, Rosti G, Hochhaus A, Soverini S, Apperley JF, Cervantes F, Clark RE, Cortes JE, Guilhot F, HjorthHansen H, Hughes TP, Kantarjian HM, Kim DW, Larson RA, Lipton JH, Mahon FX, Martinelli G, Mayer J, Müller MC, Niederwieser D, Pane F, Radich JP, Rousselot P, Saglio G, Saußele S, Schiffer C \& Silver R, Simonsson B, Steegmann JL, Goldman JM, Hehlmann R. European LeukemiaNet recommendations for the management of chronic myeloid leukemia: 2013. Blood, 2013 Aug 8;122(6):872-84

Breccia M, Stefanizzi C, Cannella L, Latagliata R, Frustaci AM, Carmosino I, Santopietro M \& Alimena G. Differences in hematological and non-hematological toxicity during treatment with imatinib in patients with early and late chronic phase chronic myeloid leukemia. Leuk Lymphoma, 2008 Dec;49(12):2328-32.

CTCAE. Available

from:

http://www.eortc.be/Services/Doc/ctc/CTCAE_4.03_2010-06-

14_QuickReference_5x7.pdf [Last accessed on 2014 February14].

Foringer JR, Verani RR, Tjia VM, Finkel KW, Samuels JA \& Guntupalli JS. Acute renal failure secondary to imatinib mesylate treatment in prostate cancer. Ann Pharmacother, 2005 Dec;39(12):2136-8. Epub 2005 Nov 15.

Gotta V, Bouchet S, Widmer N, Schuld P, Decosterd LA, Buclin T, Mahon FX, Csajka C and Molimard M. Large-scale imatinib dose-concentration-effect study in CML patients under routine care conditions. Leuk Res, 2014 Jul;38(7):764-72.

Gupta A \& Prasad K. Hematological and molecular response evaluation of CML patients on imatinib. J Assoc Physicians India, 2007 Feb;55:109-13

Hattab M.A.L. Possible Adverse Cutaneous Effects in Patients Taking Imatinib Mesylate (Gleevec ) in Treatment of Chronic Myeloid Leukemia (CML) and Gastro Intestinal Stromal Tumors ( GISTs) at Hilla City. Medical Journal of Babylon, 2013; 10( 3):537-46.
Iqbal N \& Iqbal N. Imatinib: a breakthrough of targeted therapy in cancer. Chemother Res Pract, 2014;2014:357027.

Jalaeikhoo H, Ahmadzadeh A, Toogeh G, Haybar H, Valizadeh A, Charoosaei R, Yadollahzadeh M \& Keyhani M. Six-year follow up of imatinib therapy for newly diagnosed chronic myeloid leukemia in Iranian patients. Arch Iran Med, 2011;14(6):378-80.

Mauro MJ. Striving to achieve safe, permanent treatment discontinuation in chronic myeloid leukemia. Leuk Res, 2013 Nov;37(11):1395-403.

Mendizabal AM, Garcia-Gonzalez P and Levine PH. Regional variations in age at diagnosis and overall survival among patients with chronic myeloid leukemia from low and middle income countries. Cancer Epidemiol, 2013 Jun;37(3):247-54.

Moshfeghi K, Nazemzadeh N, Mehrzad V, Hajiannejad A \& Esmaili F. Comparison of effectiveness and safety of Iranian-made vs. Indian-made imatinib in treatment of chronic myeloid leukemia. Adv Biomed Res, 2013 Mar 6;2:17.

Mozaheb Z \& Javani M. Regional Evaluation of Tolerability and Efficacy of ImatinibMesylate in Patients with Chronic Phase CML in Mashhad (Iran, Southwest Asia). Health, 2014; 6: 900-7.

O'Brien SG, Guilhot F, Larson RA, Gathmann I, Baccarani M, Cervantes F, Cornelissen JJ, Fischer T, Hochhaus A, Hughes T, Lechner K, Nielsen JL, Rousselot P, Reiffers J, Saglio G, Shepherd J, Simonsson B, Gratwohl A, Goldman JM, Kantarjian H, Taylor K, Verhoef G, Bolton AE, Capdeville $\mathrm{R} \&$ Druker BJ; IRIS Investigators. Imatinib compared with interferon and low-dose cytarabine for newly diagnosed chronic-phase chronic myeloid leukemia. N Engl J Med, 2003 Mar 13;348(11):994-1004.

Stegmeier F, Warmuth M, Sellers WR \& Dorsch M. Targeted cancer therapies in the twenty-first century: lessons from imatinib. Clin Pharmacol Ther, 2010 May;87(5):543-52.

Talpaz M, Hehlmann R, Quintás-Cardama A, Mercer J \& Cortes J. Re-emergence of interferon- $\alpha$ in the treatment of chronic myeloid leukemia. Leukemia, 2013 Apr;27(4):803-12.

Valizadeh N. Imatinib Induced Facial Skin Hyperpigmentation in a Case of Chronic Myelogenous Leukemia, 2011 Jul;12(3).

\section{How to cite this article:}

Mehrdad Payandeh, Edris Sadeghi, Masoud Sadeghi. Nonhematological Adverse Events of Imatinib in Patients with Chronic Myeloid Leukemia in Chronic Phase (CML-CP). J App Pharm Sci, 2015; 5 (02): 087-090. 